Ege Tıp Dergisi / Ege Journal of Medicine 2020; 59 (4): 241-250

\title{
Karaciğer kitlelerinin ayırıcı tanısında renkli doppler ultrasonografi ve eko kontrast madde kullanımının etkinliği
}

The effectiveness of color doppler ultrasonography and echo contrast agents

in the differential diagnosis of liver masses

İpek Tamsel(D)

Ege Üniversitesi Tıp Fakültesi, Dahili Tıp Bilimleri Bölümü, İzmir, Türkiye

Öz

Amaç: Karaciğerde kitle lezyonu saptanan olguların renkli Doppler ultrasonografi bulguları ile eko kontrast madde kullanılarak yapılan renkli Doppler ultrasonografik incelemenin kitle karakterizasyonuna katkısının literatür eşliğinde araştırılması amaçlanmıştır.

Gereç ve Yöntem: Rutin radyolojik tetkikleri sırasında karaciğerde kitle saptanan 35 olguya ait kontrastsız ve eko kontrastlı renkli Doppler bulguları retrospektif olarak değerlendirildi. Kitlede kanlanma saptanan olgularda vasküler yapılardan spektral analizler yapılarak maksimum sistolik hız (Vmax) ve rezistif indeks (Ri) değerleri ile kanlanma paternleri kaydedilmiştir. Maksimum sistolik hızların en yüksek değeri ve ona karşılık gelen Ri değerleri incelenen lezyon için belirleyici kabul edilmiştir. Lezyon tanıları biyopsi $(n=15)$ gri skala US, BT $(n=30)$, MRG $(n=27)$ ve klinik bulgular eşliğinde değerlendirilerek elde edillmiştir.

Kontrast madde öncesi ve sonrası lezyonların kanlanma paternleri ile, spektral analiz değerleri (Vmax ve $\mathrm{R}$ i) istatistiksel olarak değerlendirilmiştir.

Bulgular: Çalışmaya dahil edilen yedi olgu hemanjiom, yedi olgu hepatosellüler karsinom, yirmi olgu metastaz ve bir olgu fokal nodüler hiperplazi tanılı olgulardı. Bu lezyonların rutin renkli Doppler ultrasonografi ile kontrastlı renkli Doppler ultrasonografik değerlendirmede kanlanma paternleri grublarının istatistiksel olarak karşılaştırılmasında anlamlı ilişki bulundu. Ri değerleri arasında iki grupta istatistiksel anlamlı farklılık saptanmadı $(p<0,05)$. Vmax değerleri lezyon tanılarına göre sınıflandırıldığında her iki grup arasında istatistiksel olarak anlamlı farklılık izlenmemiştir $(p<0,05)$.

Sonuç: Olguların \%77'sinde renkli Doppler ultrasonografi tek başına tümöral lezyonların akım paternlerinin ortaya konmasında yeterli ve tatminkar sonuçların elde edilmesini sağladı. Eko kontrastı renkli Doppler ultrasonografik değerlendirme kalan olguların \%17'sinde kanlanma paterninin dinamik olarak gösterilmesi ile ayırıcı tanıya katkıda bulunmuştur.

Anahtar Sözcükler: Karaciğer kitlesi, renkli doppler ultrasonografi, eko kontrast madde.

\begin{abstract}
Aim: The aim of this study is to investigate the contribution of color Doppler ultrasonographic findings and echo enhanced color Doppler ultrasonographic evaluation to the mass characterization of patients with liver mass lesions.

Materials and Methods: Routine and echo-contrast colored Doppler findings of 35 cases with a mass in the liver during their radiological examinations were evaluated retrospectively. In cases in which blood was detected in the mass, the maximum systolic velocity (Vmax) and resistive index (RI) values and blooding patterns were recorded by performing spectral analyzes from vascular structures.
\end{abstract}

\footnotetext{
Sorumlu yazar: İpek Tamsel

Ege Üniversitesi Tıp Fakültesi, Dahili Tıp Bilimleri Bölümü, İmir, Türkiye

E-posta: ipektamsel@yahoo.com

Başvuru Tarihi: 23.12.2019 Kabul Tarihi: 12.03.2020
} 
The maximum value of the maximum systolic velocities and the corresponding $R I$ values were considered determinative for the lesion examined. Lesion diagnoses were obtained by evaluating biopsy $(n=15)$ gray scale US, CT $(n=30), M R I(n=27)$ and clinical findings. The blood flow patterns of the lesions before and after the contrast medium, spectral analysis values (Vmax and RI) were statistically evaluated.

Results: Seven patients with hemangioma, seven patients with hepatocellular carcinoma, twenty patients with metastasis and one patient with focal nodular hyperplasia were included in the study. A statistically significant correlation was found between routine color Doppler ultrasonography and echo enhanced color Doppler ultrasonographic evaluation of these lesions. There was no statistically significant difference between $R I$ values in two groups $(p<0.05)$. When Vmax values were classified according to lesion diagnoses, no statistically significant difference was observed between the two groups $(p<0.05)$.

Conclusion: Color Doppler ultrasonography in $77 \%$ of cases alone provided sufficient and satisfactory results in revealing the flow patterns of tumoral lesions. Echo-contrast colored Doppler ultrasonographic evaluation contributed to differential diagnosis by dynamically showing blood pattern in $17 \%$ of the remaining patients.

Keywords: Liver mass, color doppler sonography, echo contrast agent.

\section{Giriş}

Karaciğer kitle lezyonlarının sık yerleştiği bir organ olup, lezyonların görüntülenmesinde birçok görüntüleme yöntemi kullanılmaktadır. Ultrasonografi hepatik kitle lezyonlarının değerlendirilmesinde en sık kullanılan görüntüleme yöntemidir. Manyetik rezonans görüntüleme (MRG) ise ultrasonografi (US) ve bilgisayarlı tomografi (BT) ile saptanan lezyonların ayırıcı tanısında kullanılan ileri inceleme yöntemidir. Kesin tanı için biyopsi ile histopatolojik değerlendirme altın standart olarak tanımlanmıştır $(1,2)$.

Erken dönemde saptanan malign tümörlerin küratif tedavi şansı nedeniyle benign-malign ayrımının yapılmasının önemi artmaktadır. Ancak rutin olarak kullanılan gri skala US ile lezyon karakteristiğinin yeterli olarak yapılamadığı durumlarla karşılaşılmaktadır (3). Noninvaziv bir inceleme yöntemi olan renkli Doppler ultrasonografi (RDUS) organ ve kitle vaskülarizasyonunu göstererek benign-malign ayrımının yapılmasında halen kullanılmaktadır $(1,2)$. Karaciğer kitlelerinin ayırıcı tanısında tümör içinde ve çevresindeki kanlanma ile akım paternlerinin RDUS ile incelenmesi yöntemin temelini oluşturmaktadır. Tümörlerin yol açtığı hepatik perfüzyon değişikliklerinden faydalanarak karaciğer kitlelerinin saptanması ve kitlelerin kanlanma paternleri hakkında birtakım çalışmalar mevcuttur $(4,5)$. Kitle lezyonlarının santral ve periferindeki düşük akım volümlü ve küçük çaplı vasküler yapıların değerlendirilmesi sırasında RDUS ile sinyal elde edilmesinde bazı güçlükler yaşanabilmektedir. İntravenöz yolla kullanılan eko kontrast maddeler sistemik ve intratümöral vasküler yapılarda sinyal artışı sağlayarak, vasküler yapıların dağılımı ve konfigürasyonunun daha etkin gösterilmesine olanak sağlar. Eko kontrast madde bu etkiyi stabilize edilmiş mikrokabarcıkların kanın ekojenitesini ve Doppler sinyallerinin amplitüdünü artırması ile oluşturmaktadır (6).

Bu çalışmada gri-skala US ile saptanan karaciğer kitle lezyonlarının RDUS bulguları, sonografik kontrast madde (Levovist- SHU 508A) kullanılan olgularda kitle karakterizasyonuna katkısının araştırılması amaçlanmıştır.

\section{Gereç ve Yöntem}

$\mathrm{Bu}$ çalışmada rutin radyolojik tetkikleri sırasında kitle lezyonu saptanan 35 olguya ait eko kontrast madde ile gerçekleştirilen RDUS bulguları retrospektif olarak değerlendirildi. Renkli Doppler incelemeler tek uygulayıcı tarafından gerçekleştirilmiştir. Olguların yaş aralığı 23-77 arasında (ortalama yaş 58) olup, 21 olgu erkek, 14 olgu kadın idi.

Olgular gri skala US ve RDUS ile değerlendirildikten sonra, sonografik kontrast madde (Levovist) intravenöz yolla verilerek RDUS inceleme tekrarlanmıştır. Kitle kesin tanılarına gri skala US, BT, MRG, klinik bulgular ve biyopsiyle gidilmiştir. Biyopsi yapılmış olgularda histopatolojik tanı altın standart olarak kabul edildi. İncelemelerin tümü aynı radyolog tarafından gerçekleştirilmiştir. Gri skala US ve RDUS incelemeler 12 saat açlık sonrası yapıldı. 
Renkli Doppler ultrasonografi inceleme Toshiba SSH-140 (Tokyo, Japan) ve ATL1500, (Philips, Bothell WA) cihazlarda gerçekleştirilmiştir. Her iki cihazda sırası ile C3,75 ve C5-2 konveks problar kullanılmıştır.

Gri skala US ile kitle lokalizasyonu ve üç planda boyut ölçümü yapılmıştır. Çoklu lezyonlarda, çapı en büyük olan lezyon değerlendirmeye alınmıştır. RDUS ile lezyon kan akımı varlığı, spektral analizi ve kanlanma paterni değerlendirilmiştir. İncelemelerde renk kutusu genişliği lezyonun tamamını ve çevresindeki kanlanmayı gösterecek şekilde ayarlanmıştır. Spektral analizlerde Doppler örnekleme volümü incelenen damarsal yapının çapından küçük olacak şekilde, Doppler açısı 30-60 derece arasında ayarlanmıştır. Duvar filtresi $50 \mathrm{MHz}$ veya daha düşük düzeylerde çalışıldı. Vuru (puls) tekrarlama sıklığı 'aliasing' oluşturmayan ve en net sinyallerin elde edildiği aralıklarda tutulmuştur.

Tüm olgulara kontrast madde olarak SHU $508 \mathrm{~A}$ (Levovist, Schering, Almanya) $300 \mathrm{mg} / \mathrm{ml}$ konsantrasyonda kullanılmıştır. Galaktoz içeren flakonlardan hazırlanan $8,5 \mathrm{ml}$ süspansiyon bolus enjeksiyon şeklinde antekubital venden verilmiştir. Kontrast madde öncesi değerlendirilen tüm parametreler enjeksiyon sonrası tekrar değerlendirilmiştir.

Lezyonların kanlanma özellikleri şu şekilde sınıflandırılmıştır:

I -Lezyon çevresindeki kanlanmaya göre;

Grup 1: Kanlanma saptanmadı.

Grup 2: Bir ya da iki adet damarsal yapı.

Grup 3: Üç ve daha fazla sayıda damarsal yapı.

II- Lezyon içindeki kanlanmaya göre;

Grup A: Kanlanma saptanmadı.

Grup B: Bir ya da iki adet damarsal yapı.

Grup C: Üç ve daha fazla sayıda damarsal yapı.

Kanlanma saptanan olgularda kitlesel lezyona ait vasküler yapılardan spektral analizler yapılarak maksimum sistolik hiz (Vmax) ve rezistif indeks (Ri) değerleri kaydedilmiştir. Maksimum sistolik hızların en yüksek değeri ve ona karşılık gelen Ri değerleri incelenen lezyon için belirleyici kabul edilmiştir.

Lezyonlar kesin tanılarına göre dört gruba ayrılmıştır (Hemanjiom, hepatosellüler karsinom (HSK), metastaz, fokal nodüler hiperplazi). Kanlanma özellikleri, paternleri ve spektral analizleri bu gruplara göre sınıflandırılmıştır.
Hepatosellüler karsinomlar için tipik olarak kabul edilen 'basket' tipi kanlanma paterninde tümöral damarsal yapılar kitle lezyonunu çevreleyerek, lezyon içine doğru dallanma gösterir. Hepatosellüler karsinomlar için diğer kanlanma paterni ise tümör içerisinde kaotik karakterde damarsal yapıların izlendiği 'vessel'in tümör paternidir. Metastatik kitle lezyonları için portal venin tümöral nodüller çevresinden dolaştığı ve tümör içi uzanım ve dallanma bulunmayan 'detour' kanlanma paterni tanımlanmıştır. Hemanjiomlarda tanımlanan 'spot' paternde ise tümörün santral kesiminde noktasal (benek) veya yama tarzında kanlanma izlenir. Fokal nodüler hiperplaziler için 'spoke-wheel' patern tanımlanmıştır. Bu paternde kitle lezyonu santral kesiminden perifere doğru uzanan araba tekerleği görünümünde damarlanmalar mevcut olup, bu lezyon için patognomonik olarak kabul edilmektedir.

Kontrast madde öncesi ve sonrası lezyonların kanlanma özellikleri Kendall's nonparametrik korelasyon testi ile, spektral analiz değerleri (Vmax ve Ri) ise Wilcoxon Signed Ranks ve Kruskal Wallis testleri ile istatistiksel olarak değerlendirilmiştir.

\section{Bulgular}

Karaciğerde kitle lezyonu bulunan toplam 35 olgu değerlendirilmiştir. Lezyonların kesin tanıları gri skala US, BT $(n=30)$, MRG $(n=27)$, biyopsi $(n=15)$ ve klinik bulgular eşliğinde değerlendirilerek elde edillmiştir. Yedi olgu hemanjiom, yedi olgu HSK, yirmi olgu metastaz ve bir olgu ise fokal nodüler hiperplazi $(\mathrm{FNH})$ kesin tanılı olgulardı.

Metastatik lezyonlar primer orjinlerine göre gastrointestinal sistem (kolon ve mide) $(n=8)$, adenokarsinom (primeri bilinmeyen) $(n=6)$, genitoüriner sistem $(n=2)$, pankreas $(n=1)$, safra kesesi $(n=1)$, nazofarinks $(n=1)$ ve malign melanoma $(n=1)$ olarak dağılım göstermekteydi.

Lezyonların çapları 1,5 ile $13 \mathrm{~cm}$ arasında ölçüldü. Çoklu lezyonlarda lezyon boyutu en büyük olan kitle lezyonu değerlendirilmiştir.

Incelenen 35 lezyonun 33'ünde (\%94) RDUS ile kitlede kanlanma gösterilmiştir. Kanlanma saptanmayan (grup 1A) iki lezyondan bir olgu hemanjiom, diğeri ise metastaz tanılı idi. $\mathrm{Bu}$ olgularda kontrast madde sonrası damarsal kodlanma saptanmamıştır. Sadece bir metastatik lezyon dışında tüm malign tanı almış kitlelerde çevresel ya da lezyon içi kanlanma görülmüştür. 
Tablo-1. Lezyonların kontrast öncesi ve sonrası kanlanma paterni, Vmax ve Rì değerleri.

\begin{tabular}{|c|c|c|c|c|c|c|}
\hline \multicolumn{4}{|c|}{ Kontrast Öncesi } & \multicolumn{3}{|c|}{ Kontrast Sonrası } \\
\hline OLGU & $\begin{array}{l}\text { Kanlanma } \\
\text { paterni }\end{array}$ & $\begin{array}{l}\text { Vmax } \\
\text { (m/sn) }\end{array}$ & $\mathbf{R} \mathbf{i}$ & $\begin{array}{l}\text { Kanlanma } \\
\text { paterni }\end{array}$ & $\begin{array}{l}\text { Vmax } \\
\text { (m/sn) }\end{array}$ & $\mathbf{R} \mathbf{i}$ \\
\hline 1-HSK & $2 \mathrm{~B}$ & 0,50 & 0,53 & $3 B$ & 0,53 & 0,50 \\
\hline 2-Metastaz & $2 \mathrm{~A}$ & 0,29 & 0,58 & $3 A$ & 0,31 & 0,62 \\
\hline 3-Metastaz & $2 \mathrm{~A}$ & 0,30 & 0,67 & $2 \mathrm{~A}$ & 0,28 & 0,69 \\
\hline 4-Metastaz & $1 \mathrm{~A}$ & - & - & $1 \mathrm{~A}$ & - & - \\
\hline 5-Metastaz & 1B & 0,37 & 0,50 & $1 \mathrm{C}$ & 0,36 & 0,52 \\
\hline 6-HSK & $2 \mathrm{~B}$ & 0,41 & 0,55 & $2 \mathrm{C}$ & 0,40 & 0,53 \\
\hline 7-HSK & $2 \mathrm{C}$ & 0,43 & 0,68 & $3 C$ & 0,45 & 0,70 \\
\hline 8-Metastaz & $2 \mathrm{C}$ & 0,18 & 0,55 & $3 C$ & 0,20 & 0,53 \\
\hline 9-Metastaz & $2 A$ & 0,42 & 0,49 & $3 A$ & 0,42 & 0,50 \\
\hline 10-HSK & $3 A$ & 0,30 & 0,75 & $3 B$ & 0,31 & 0,73 \\
\hline 11-HSK & $2 \mathrm{~B}$ & 0,23 & 0,72 & $3 B$ & 0,25 & 0,71 \\
\hline 12-Hemanjiom & $2 \mathrm{~A}$ & - & - & $2 B$ & - & - \\
\hline 13-Metastaz & $2 \mathrm{C}$ & 0,72 & 0,85 & $3 C$ & 0,74 & 0,87 \\
\hline 14-Metastaz & $2 A$ & 0,20 & 0,48 & $2 A$ & 0,22 & 0,49 \\
\hline 15-Hemanjiom & $2 \mathrm{~A}$ & 0,53 & 0,66 & $2 \mathrm{C}$ & 0,53 & 0,65 \\
\hline 16-Metastaz & $2 \mathrm{~A}$ & 0,18 & 0,60 & $3 A$ & 0,19 & 0,60 \\
\hline 17-HSK & $3 A$ & 0,59 & 0,68 & $3 C$ & 0,60 & 0,71 \\
\hline 18-Metastaz & $2 A$ & 0,42 & 0,66 & $2 A$ & 0,42 & 0,65 \\
\hline 19-Metastaz & $2 \mathrm{~A}$ & 0,47 & 0,58 & $3 A$ & 0,48 & 0,60 \\
\hline 20-Metastaz & $2 \mathrm{~A}$ & 0,58 & 0,61 & $2 B$ & 0,58 & 0,62 \\
\hline 21-Hemanjiom & $2 \mathrm{~A}$ & - & - & $2 \mathrm{C}$ & - & - \\
\hline 22-Metastaz & $2 \mathrm{~A}$ & 0,72 & 0,65 & $3 B$ & 0,73 & 0,63 \\
\hline 23-HSK & $2 \mathrm{~A}$ & 0,25 & 0,65 & $2 \mathrm{~A}$ & 0,25 & 0,68 \\
\hline 24-Metastaz & $2 \mathrm{~A}$ & 0,42 & 0,57 & $2 \mathrm{~B}$ & 0,41 & 0,57 \\
\hline 25-FNH & 1B & 0,53 & 0,58 & $2 \mathrm{C}$ & 0,54 & 0,61 \\
\hline 26-Metastaz & $2 \mathrm{~A}$ & 0,98 & 0,75 & $2 \mathrm{C}$ & 1,00 & 0,76 \\
\hline 27-Hemanjiom & $1 \mathrm{~A}$ & - & - & $1 \mathrm{~A}$ & - & - \\
\hline 28-Metastaz & $2 A$ & 0,54 & 0,65 & $3 A$ & 0,54 & 0,63 \\
\hline 29-Metastaz & $2 A$ & - & - & $2 \mathrm{~B}$ & - & - \\
\hline 30-Metastaz & $3 A$ & 0,51 & 0,67 & $3 C$ & 0,51 & 0,65 \\
\hline 31-Metastaz & $2 \mathrm{~A}$ & 0,50 & 0,65 & $3 A$ & 0,51 & 0,65 \\
\hline 32-Metastaz & $1 \mathrm{~B}$ & 0,11 & 0,53 & $1 \mathrm{~B}$ & 0,12 & 0,55 \\
\hline 33-Hemanjiom & $2 \mathrm{~A}$ & 0,72 & 0,51 & $3 C$ & 0,71 & 0,51 \\
\hline 34-Hemanjiom & $2 \mathrm{~A}$ & - & - & $2 \mathrm{C}$ & - & - \\
\hline 35-Hemanjiom & $2 \mathrm{~B}$ & 0,18 & 0,60 & $2 \mathrm{C}$ & 0,18 & 0,60 \\
\hline
\end{tabular}

HSK : Hepatosellüler karsinom

FNH : Fokal Nodüler Hiperplazi

Ri : Rezistif indeks

Vmax : Maksimum sistolik hız 
Tablo-2. Kontrast öncesi ve sonrası lezyonlarda saptanan kanlanma paternleri.

\begin{tabular}{|c|c|c|c|c|c|c|c|c|c|c|c|c|c|c|c|c|c|c|}
\hline & \multicolumn{9}{|c|}{ Kontrast Öncesi } & \multicolumn{9}{|c|}{ Kontrast Sonrası } \\
\hline & $1 \mathrm{~A}$ & $1 \mathrm{~B}$ & $1 \mathrm{C}$ & $2 A$ & $2 B$ & $2 \mathrm{C}$ & $3 A$ & $3 B$ & $3 C$ & $1 \mathrm{~A}$ & $1 \mathrm{~B}$ & $1 \mathrm{C}$ & $2 A$ & $2 \mathrm{~B}$ & $2 \mathrm{C}$ & $3 A$ & $3 B$ & $3 C$ \\
\hline Hemanjiom & 1 & & & 5 & 1 & & & & & 1 & & & & 1 & 4 & & & 1 \\
\hline HSK & & & & 1 & 3 & 1 & 2 & & & & & & 1 & & & & 3 & 3 \\
\hline Metastaz & 1 & 2 & & 14 & & 2 & 1 & & & 1 & 1 & 1 & 3 & 3 & 1 & 6 & 1 & 3 \\
\hline FNH & & 1 & & & & & & & & & & & & & 1 & & & \\
\hline
\end{tabular}

HSK : Hepatosellüler karsinom

FNH : Fokal nodüler hiperplazi

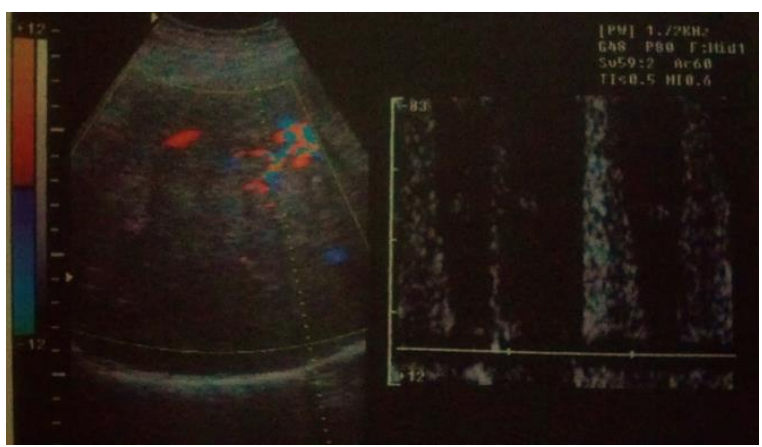

(a)

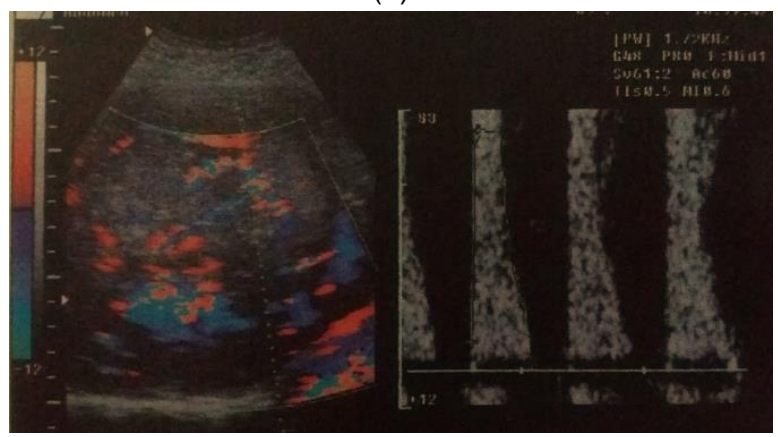

(b)

Şekil-1. Hepatosellüler karsinom tanılı olguda (a) lezyon periferinde besleyici arteriyel yapı (ok) izlenmekte. (b) Eko kontrast madde ardından besleyici arteriyel yapının lezyon içerisine dallar verdiği ve renk kodlanmasında artış olduğu görülmektedir.

Kontrast madde sonrası yedi lezyonda (beş metastaz, bir hemanjiom, bir HSK olgusu) kanlanma gruplarında değişiklik saptanmazken; 28 olguda kanlanma sınıflandırmasında farklılık olduğu görülmüştür. Lezyonların kanlanma özellikleri, Vmax ve Ri değerleri kontrast öncesi ve sonrası olmak üzere Tablo-1' de gösterilmiştir.

Rutin RDUS ile HSK tanısı almış yedi olgudan beşinde (\%71) 'basket', bir olguda 'vessel's in tumor' paterni izlenmiştir. Bir olgu ise hipovasküler karakterde idi. Eko kontrast madde sonrası 'basket' patern izlenen beş olgudan dördünde besleyici arter daha iyi görüntülenmiştir (Şekil-1). Hipervasküler lezyonda ise kontrast sonrası belirgin vaskülarite artışı gözlenmiştir (Şekil-2).

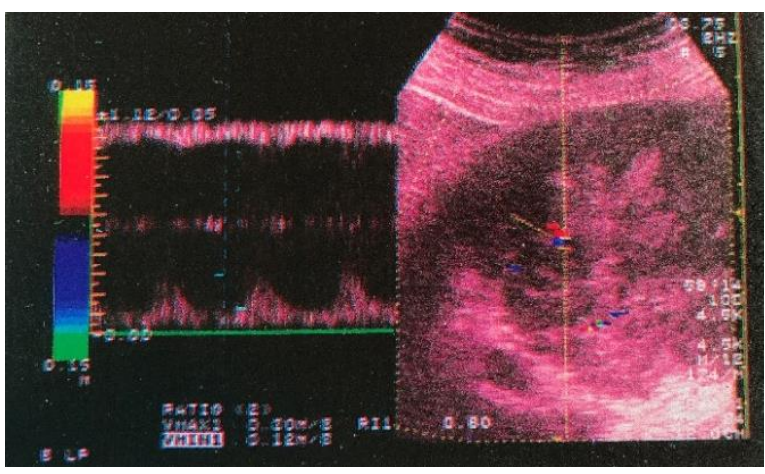

(a)

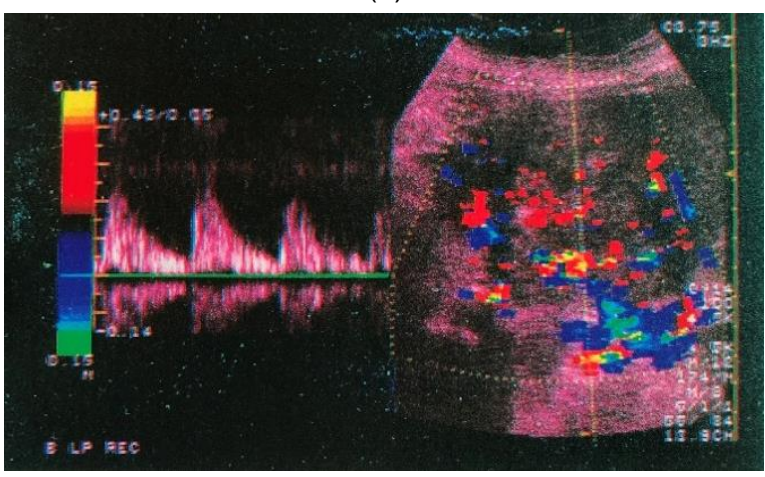

(b)

Şekil-2. Hepatoma tanılı olguda (a) lezyon periferinde birkaç adet vasküler kodlanma (ok), (b) kontrast sonrası incelemede lezyon periferi ve santralinde sayı ve sinyal artışı gösteren kaotik vasküler yapılar görülmüştür. 


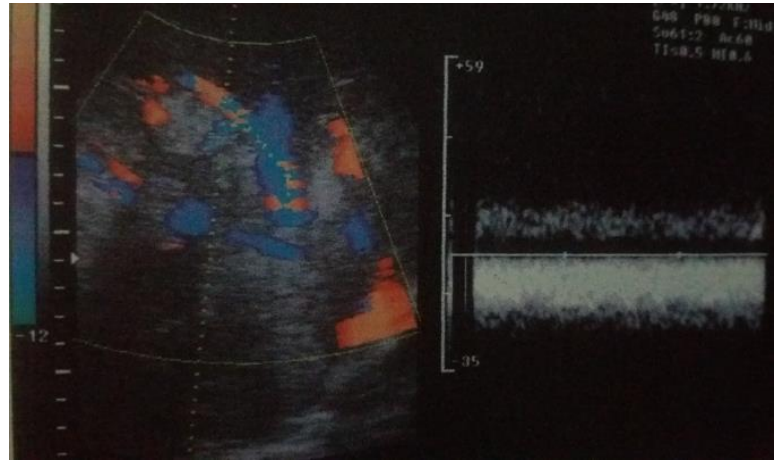

Şekil-3. Metastaz tanılı olguda kontrast madde sonrası lezyon periferinde dilate portal venöz yapı (ok) izlenmiştir.

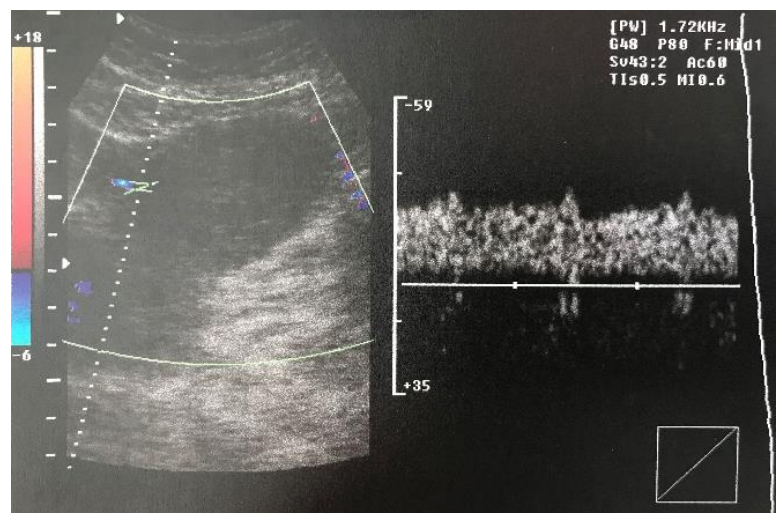

(a)

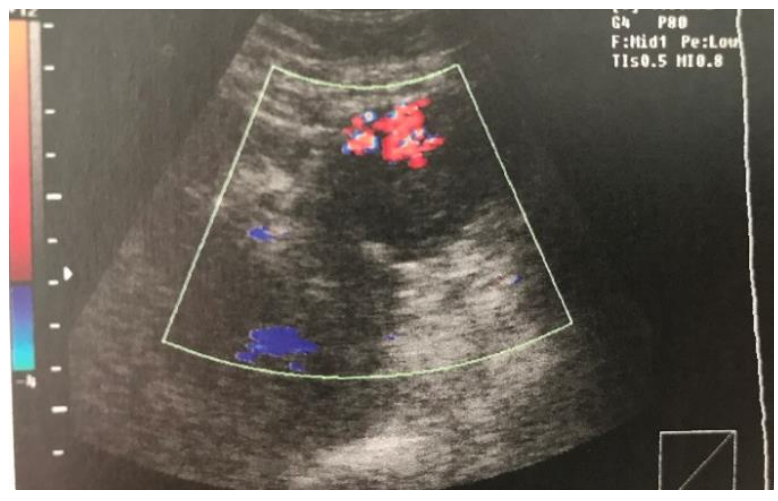

(b)

Şekil-4. Hemanjiom tanılı olguda (a) lezyon periferinde arteriyo-venöz şant akım formu gösteren vasküler yapı, (b) kontrast madde ardından lezyon içi yamasal vasküler kodlanma (ok) izlenmekte.

Metastaz tanılı 10 olguda lezyonlar hipovasküler özellikte olup sadece lezyon çevresinde vasküler kodlanma saptanmıştır (Şekil-3). Eko kontrast sonrası değerlendirmede lezyon içi vasküler kodlanma izlenmedi. Dokuz olguda kitle içi arteriyel akım formuna sahip vasküler yapılar izlenmiştir. $\mathrm{Bu}$ lezyonlarda kontrast sonrası vasküler kodlanmada artış olduğu görülmüştür.

Hemanjiom tanılı bir olguda kontrast öncesi ve sonrası vasküler kodlanma saptanmamıştır. Beş olguda kontrast madde sonrası tipik 'spot' patern izlenmiştir (Şekil-4).

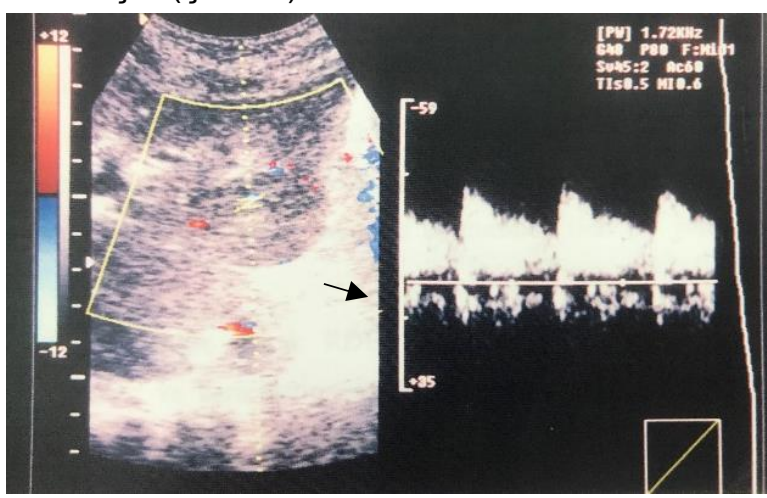

(a)

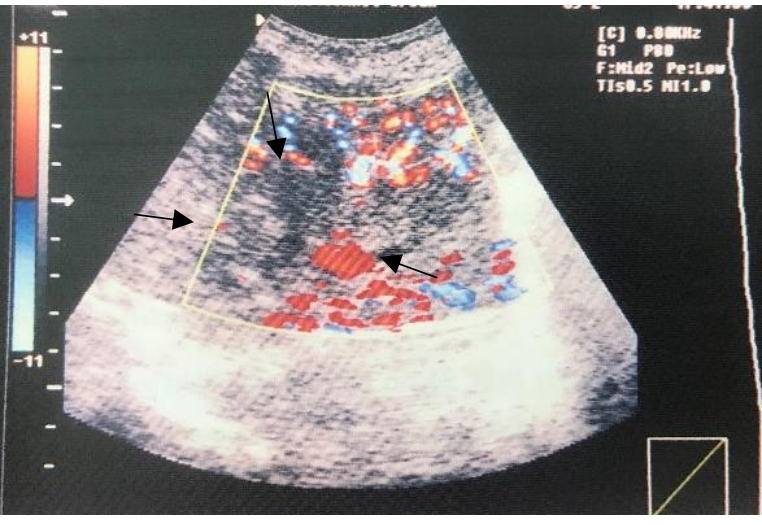

(b)

Şekil-5. Fokal nodüler hiperplazi olgusunda (a) lezyon içerisinde santral skara ait vasküler kodlanma (ok), (b) kontrast madde sonrası santralden perifere ışınsal uzanım gösteren vasküler yapılar (ok) dinamik olarak görüntülenmiştir.

Fokal nodüler hiperplazi olgumuzda kontrast öncesi lezyon santralinde tek bir vasküler yapı kodlanırken, kontrast madde sonrası santralden perifere uzanan tipik 'spoke wheel' patern izlenmiştir (Şekil-5).

Kontrast madde öncesi ve sonrası lezyonların tanılarına göre kanlanma paternleri dağılımı Tablo-2'de verilmiştir.

Kanlanma saptanan 33 lezyonun yapılan spektral analizinde dört lezyonda venöz tip, 29 lezyonda ise arteriyel ve / veya venöz tip akım dalga formları kaydedilmiştir. Yapılan ölçümlerde Vmax ve RI değerleri Tablo-1'de gösterilmiştir. 
Verilerin istatistiksel analizi: Eko kontrast öncesi RDUS incelemede tutarlılık 0,54 olarak hesaplanmıştır. Kontrast madde kullanımı ardından tanı koymada tutarlılık 0,88'e yükselmiştir. Eko kontrast madde kullanımı tanı koymada tutarlıığı arttırmakla birlikte istatistiksel anlamlı bir fark mevcut değildir.

Rutin RDUS ile kontrastlı RDUS değerlendirmede lezyonların kanlanma paternleri grublarının istatistiksel olarak karşılaştırılmasında (Kendall's nonparametrik korelasyon testi ile) anlamlı ilişki bulundu. Lezyon hipervasküler ise kontrastlı değerlendirmede o oranda ya da daha fazla vaskülarizasyon gösterdiği saptandı.

Rezistif indeks değerleri arasında iki grupta istatistiksel anlamlı farklılık saptanmadı (Wilcoxon Signed Ranks test, $\mathrm{p}<0,05)$.

Maksimum sistolik hız (Vmax) değerleri lezyon tanılarına göre sınıflandırıldığında her iki grup arasında istatistiksel olarak anlamlı farklılık izlenmemiştir (Kruskal Wallis test, $p<0,05$ ).

\section{Tartışma}

Doppler ultrasonografi abdominal organların kanlanması ve organ perfüzyonlarının değerlendirilmesi yanı sıra tümöral damarlanmalar ile tümör hemodinamiği hakkında önemli veriler sağlamaktadır $(4,5)$. Renkli Doppler ultrasonografi inceleme hepatik arteriyel, venöz ve portal sistem akım özelliklerinin görüntülenmesinde ilk başvurulan görüntüleme yöntemidir (7).

Ultrasonografik kontrast madde kullanma fikri ilk olarak 1968 yılında Gramiak ve arkadaşları tarafından ortaya atılmıştır. Hepatik tümörlerin görüntülenmesinde eko kontrast maddelerin etkin olduğunu ilk gösteren araştırmacılar Goldberg ve arkadaşları olmuştur. Kontrast madde kullanımı ile Doppler sinyalleri arttırılarak küçük çaplı ve derin yerleşimli vasküler yapıların görüntülenebilirliği artmıştır (8).

Eko kontrast ajanlar hastalar tarafından iyi tolere edilir ve iyi bir güvenlik profiline sahiptir. Anafilaktoid reaksiyon, nadir görülen yan etkileri olup, BT görüntülemesi için kullanılan kontrast ajanlardan çok daha düşüktür. Bu ajanların diğer avantajları arasında iyot alerjisi olan olgular ile böbrek fonksiyon bozukluğu varlığında güvenle kullanılabilmeleridir (9).

Eko kontrast madde kullanılarak yapılan incelemeler lezyonun kanlanma paterninin dinamik olarak da gösterilmesine olanak sağlar. Arteryel faz 10-20 sn içinde başlar ve enjeksiyondan sonra yaklaşık 35-40 sn devam eder. Portal venöz faz enjeksiyondan sonra 2 dakikaya kadar sürer ve karaciğer parankiminin homojen olarak kontrastlanması ile karakterizedir. Geç faz ise 5-6 dakika devam eder $(9,10)$.

Malign lezyonlarda (hepatosellüler karsinoma, metastaz vb.) genellikle erken vasküler fazda belirgin kontrast tutulumu olurken, geç parankimal fazda perfüzyon defekti şeklinde izlenirler. Benign lezyonlarda ise, erken vasküler fazda kontrast tutulumu izlenmekle birlikte geç parankimal fazda perfüzyon persistansı izlenir $(11,12)$.

Kontrastlı ultrasonografik incelemenin, konvansiyonel ultrasonografiye göre HCC dahil malign karaciğer lezyonlarının tespitinde doğruluk oranlarını artırdığı bildirilmiştir (13).

Literatürde yapılan çalışmalar HSK'nin karaciğerde en sık görülen malign tümör olması nedeniyle bu lezyonlarda yoğunlaşmıştır. Farklı araştırmacıların RDUS ile yaptıkları çalışmalarda HSK için tipik olarak kabul edilen iki patern tanımlamıştır. Tanaka ve arkadaşları 'basket' ve 'vessel's in tumor' paternlerinin HSK için karakteristik olduğunu belirtmişlerdir (5). Pennisi ve arkadaşları tarafından yapılan bir çalışmada eko kontrast madde kullanımı sonrası RDUS ile HSK olgularında 'basket' patern gösterilmiştir (14).

Tanaka ve arkadaşları bir diğer çalışmalarında kontrast öncesi tümöral lezyonların besleyici arterinin gösterilebilme oranı \%43 iken, kontrast sonrası değerlendirmede \%95'lere dek ulaştığını bildirmiştir (15).

Bizim çalışmamızda HSK tanılı yedi olgunun beşinde (\%71) RDUS ile 'basket' patern gösterildi. Bu olgulardan dördünde eko kontrast madde sonrası besleyici arter ve dalları daha etkin olarak gösterildi. Eko kontrast madde verilmesi ile lezyon içi vasküler kodlanmalarda artış saptandı.

Karaciğer malign infiltrasyonunun en sık nedeni karsinom metastazlarıdır. Metastazlar, arteryel fazda hipo veya hipervasküler olabilir veya periferal kontrastalanma izlenebilir. Bütün metastazlar portal faz ve geç fazda kontrastı verirler (washout) (16). Çeşitli araştırmacılar metastazlar için 'detour' paterni (portal vende dilatasyon, ven veya dallarının tümöral nodüller çevresinde seyir gösterdiği) tanımlanmıştır. Vasküler yapılar bu paternde basket paternin aksine kitle içerisine doğru uzanım göstermezler 
(5). Nino-Murcia ve arkadaşları hepatik metastazlarda sıklıkla santral kanlanma saptamadıklarını (\%67) bildirmişlerdir (4). Fujimoto ve arkadaşları metastatik lezyonların çevresinde geniş arteriyel vasküler yapıların varlığını göstermişlerdir (17). Çalışmamızda metastaz olgularının \%50'si hipovasküler karakterdeydi. Olguların \%45'inde lezyonlar hipervasküler olup, eko kontrast madde vasküler kodlanmayı artırmıştır. Bu patern HSK için tanımlanan 'vessel's in tumor' paternine benzer görünüme sahipti. Bu lezyonlarda malign karakter tanımlanmış ancak HSK ile metastaz ayrımı zorlaşmıştır.

Hemanjiomlar için kitle içerisinde nokta-benek veya yama tarzı vasküler kodlanmalar 'spot' patern tanımlanmıştır. Bu vasküler yapının spektral analizinde genellikle venöz (nonpulsatil) akım saptanmıştır. Ancak arteriyel tip kanlanma saptanması hemanjiomu ekarte ettirmemektedir $(5,7,18)$. Naganuma ve arkadaşları hemanjiomlarda arteriyoportal şant varlığını göstermiş̧ir (19). Çalışmamıza dahil olan yedi hemanjiom olgusundan biri (\%14) grup $1 \mathrm{~A}$ olup, vasküler kodlanma izlenmedi. Beş olguda (\%72) diffüz ya da yama tarzı periferden santrale doğru kontrastlanmanın gösterilmesi tanı koydurucu oldu. Olgulardan üçünde arteriyovenöz şant özelliği gösteren akım formları kaydedildi.

Yapılan pek çok çalışma ile FNH için RDUS ile merkezi skar ve septasyonlar içerisinde arteriyel akım formu gösteren tipik kanlanma paterni 'spoke wheel' tanımlanmıştır. Anjiografik olarak santralden septalar boyunca uzanım gösteren sentripedal afferent dallar $\mathrm{FNH}$ için özgün olarak kabul edilmiştir $(7,20,21)$.

Çalışmamızdaki tek FNH olgusunda kontrast madde öncesi RDUS ile lezyon merkezinde arteriyel akım formu gösteren tek bir vasküler yapı (santral skar) gösterilmiştir. Kontrast kullanımı sonrası tipik olarak tanımlanan 'spoke wheel' patern görüntülendi.

Tüm olgular birlikte değerlendirildiğinde hemanjiom tanısı alan beş olgu ile tek FNH olgusunda eko kontrast madde kullanımı sonrası tipik paternler gösterilmiştir. Kontrast madde kullanılması altı olguda ayırıcı tanıya katkı sağlamıştır. Metastatik lezyonlar için yalnızca 'detour' patern gösterilen olgularda (10/20) ayırıcı tanıya gidilmiştir. Çalışmamızın sınırlıı̆ı toplam olgu sayısı ile lezyon çeşitliliğinin az olmasıdır.

Doppler spektral analizlerinin ayırıcı tanıda kullanımı ile ilgili literatürde pek çok çalışma mevcuttur. Maksimum sistolik hiz (Vmax) değerlerinin diğer lezyonlara göre malign lezyonlarda daha yüksek olduğunu bildiren makaleler yayınlanmıştır (22). Numata ve arkadaşları $0,40 \mathrm{~m} / \mathrm{sn}$ üzerindeki $V \max$ değerlerinin malign hepatik lezyonları hemanjiomlardan ayırtedebileceğini savunmuşlardır (23). Bulgularımız Vmax değerlerinin HSK ile metastaz ayrımında kullanılamayacağını göstermiştir. Ayrıca $\mathrm{FNH}$ ve hemanjiom olgularında $0,40 \mathrm{~m} / \mathrm{sn}$ aşan değerler mevcuttur. $\mathrm{Bu}$ nedenle Vmax değerleri benign-malign ayrımında bizim çalışmamızda tanıya katkı sağlamamıştır. Rezistif indeks değerleri istatistiksel olarak kontrast madde kullanımı ile anlamlı farklılık göstermemektedir. Yüksek RI değerleri benign ve malign lezyonlarda kaydedilmiş olup, Ri değerleri ayırıcı tanıya katkı sağlamadığı görülmüştür.

Literatürde bildirilen eko kontrastlı çalışmalarda rastlantısal olarak bulunan solid karaciğer lezyonları için dinamik görüntüleme yapılarak kontrastlı MRG'ye benzer tanısal doğruluk oranları bildirilmiştir. Trillaud ve arkadaşları tarafından yapılan çalışmada benign ve malign lezyonların karakterizasyonu için, BT veya MRG'ye (sırasıyla\% 68,5 ve 74,6 ) kıyasla eko kontrastlı sonografinin duyarlıı̆̆ $\% 98,2$, özgüllüğü \% 88,1 olarak bildirilmiştir (24). Bu açıdan kontrastlı sonografik incelemeler ultrasonografi ile saptanan kitle lezyonlarında ikinci olarak seçilecek görüntüleme yöntemi olarak kabul görmektedir. Bu durum özellikle benign lezyonlar için daha pahalı araştırmalardan kaçınmak ve gereksiz biyopsi işleminin önlenmesi açısından önem taşımaktadır. $(25,26)$.

\section{Sonuç}

Renkli Doppler ultrasonografi abdominal ve pelvik organların kanlanması ve perfüzyonun değerlendirilmesi yanısıra tümöral damarlanma hakkında veri elde edilmesinde kullanılan bir görüntüleme yöntemidir. Eko kontrast madde kullanımı ile derin yerleşim gösteren, zayıf Doppler sinyalleri nedeniyle görüntülenemeyen vasküler yapıların daha kolay izlendiği saptanmıştır.

Çalışmamıza dahil olan olguların \%77'sinde RDUS tek başına tümöral lezyonların akım paternlerinin ortaya konmasında yeterli ve tatminkar sonuçların elde edilmesini sağladı. Kalan \%22 olgudan \%17' sinde eko kontrast madde kullanımı kanlanma paterninin dinamik olarak gösterilmesini sağlayarak ayırıcı tanıya önemli oranda katkıda bulunmuştur. Eko kontrast madde tanı koymada tutarlılığı arttırmış, ancak 
istatistiksel olarak anlamlı bir farklılığa yol açmamıştır.

Eko kontrast madde kullanımı özellikle böbrek yetmezliği olan olgularda MRG ve BT çekilemeyen durumlarda tercih edilebilir. Karaciğerde çoklu lezyonların tek enjeksiyonla incelenmesindeki problemler ile ultrasonografik incelemeye ait derin lezyonlarda ve obez olgularda penetrasyon zorluğu gibi dezavantajları bulunmaktadır. Ultrasonografik tekniklerin gelişimi ile birlikte eko kontrast madde kullanımı dinamik görüntülemeye olanak sağlanmaktadır.
Literatürde yapılan çalışmalarda eko kontrastlı incelemenin kitle karakterizasyonundaki başarısının kontrastlı dinamik MRG ile eş değer olduğu bildirilmiştir. Günümüzde eko kontrastlı ultrasonografik inceleme, fokal karaciğer lezyonlarının ultrasonografi ile saptanması ardından ikinci sırada başvurulacak bir tanı yöntemi olarak önerilmektedir.

\section{Çıkar çatışması}

Yazarlar arasında çıkar çatışması bulunmamaktadır.

\section{Kaynaklar}

1. Leen E, Goldberg JA, Robertson J, et al. Detection of hepatik metastasis using duplex/ color Doppler sonography. Ann Surg. 1991; 214 (5): 599-604.

2. Leen E, Goldberg JA, Robertson J, et al. Image directed Doppler sonography; a novel technique for diagnosis of colorectal liver metastasis. J Clin Ultrasound 1993; 21: 221-30.

3. Paintner A, Bayer C, Böttcher B, Wenk H, Swobodnik W. Doppler and color Doppler ultrasound diagnosis in differentiation of focal liver lesions. Bildgebung. 1996; 63 (1): 22-6.

4. Nino-Murcia M, Ralls PW, Jeffrey RB Jr, Johnson M. Color flow Doppler characterization of focal hepatic lesions. AJR Am J Roentgenol. 1992; 159 (6): 1195-7.

5. Tanaka S, Kitamura T, Fujita M, Nakanishi K, Okuda S. Color Doppler flow imaging of liver tumors. AJR Am J Roentgenol. 1990; 154 (3): 509-14.

6. Goldberg BB, Liu JB, Forsberg F. Ultrasound contrast agents: A review. Ultrasound Med Biol. 1994; 20 (4): 319-33.

7. Killi RM. Doppler sonography of the native liver. Eur J Radiology 1999; 32 (1): 21-35.

8. Ernst H, Hahn EG, Balzer T, Schlief R, Heyder N. Color doppler ultrasound of liver lesions: signal enhancement after intravenous injection of the ultrasound contrast agent Levovist. J Clin Ultrasound. 1996; 24 (1): 31-5.

9. Claudon M, Dietrich CF, Choi BI, D O Cosgrove, M Kudo, C P Nolsøe, et al. Guidelines and good clinical practice recommendations for contrast enhanced ultrasound (CEUS) in the liver-update 2012: a WFUMBEFSUMB initiative in cooperation with representatives of AFSUMB, AIUM, ASUM, FLAUS and ICUS. Ultraschall Med 2013; 34 (1):11-29.

10. Nicolau C, Vilana R, Catala V, Bianchi L, Gilabert R, García A, et al. Importance of evaluating all vascular phases on contrast-enhanced sonography in the differentiation of benign from malignant focal liver lesions. AJR Am J Roentgenol 2006; 186 (1): 158-67.

11. Harvey CJ, Blomley MJK, Eckersley RJ, Cosgrove DO. Developments in ultrasound contrast media. Eur Radiol 2001; 11 (4): 675-89.

12. Tanaka S, loka T, Oshikawa O, Hamada Y, Yoshioka F. Dynamic sonography of hepatic tumors. AJR Am J Reontgenol 2001; 177 (4): 799-805.

13. Chami L, Lassau N, Malka D, Ducreux M, Bidault S, Roche A, et al. Benefits of contrastenhanced sonography for the detection of liver lesions: comparison with histologic findings. AJR Am J Roentgenol 2008; 190: 68390.

14. Pennisi F, Farina R, Politi G, Lombardo R, Puleo S. Hepatic focal lesions: role of color Doppler ultrasonography with contrast media. Radiol Med. 1998; 96 (6): 579-87.

15. Tanaka S, Kitamra T, Fujita M, Yoshioka F. Value of contrast-enhanced color Doppler sonography in diagnosing hepatocellular carcinoma with special attention to the "color-filled pattern". J Clin Ultrasound. 1998; 26 (4): 207-12.

16. Sandulescu L, Saftoiu A, Dumitrescu D, Ciurea T. The Role of Real-time contrast-enhanced and real-time virtual sonography in the assessment of malignant liver lesions. J Gastrointestin Liver Dis 2009: 18 (1): 103-8. 
17. Fujimoto M, Moriyasu F, Nishikawa K, Nada T, Okuma M. Color Doppler sonography of hepatic tumors with a galactose-based contrast agent: correlation with angiographic findings. AJR Am J Roentgenol. 1994; 163 (5): 1099-104.

18. Wachsberg RH1, Jilani M. Duplex Doppler sonography of small ( $<3 \mathrm{~cm}$ diameter) liver tumours: intralesional arterial flow does not exclude cavernous haemangioma. Clin Radiol. 1999; 54(2): 103-6.

19. Naganuma $\mathrm{H}$, Ishida $\mathrm{H}$, Konno $\mathrm{K}$, et al. Hepatic hemangioma with arterioportal shunts. Abdominal Imaging 1999; 24, 42-6.

20. Nishigaki $Y$, Tomita E, Matsuno $Y$, et al. Usefulness of novel imaging modalities in diagnosis of focal nodular hyperplasia of the liver. Journal of Gastroenterology 1997; 32, 677-83.

21. Wang LY1, Wang JH, Lin ZY, et al. Hepatic focal nodular hyperplasia: findings on color Doppler ultrasound. Abdom Imaging. 1997; 22 (2): 178-81.

22. Reinhold C, Hammers L, Taylor CR, Quedens-Case CL, Holland CK, Taylor KJ. Characterization of focal hepatic lesions with duplex sonography: findings in 198 patients. AJR Am J Roentgenol. 1995; 164 (5): $1131-5$.

23. Numata K, Tanaka K, Kiba T, et al. Use of hepatic tumor index on color Doppler sonography for differentiating large hepatic tumors. AJR 1997; 168 (4): 991-5.

24. Trillaud H, Bruel J-M, Valette P-J, Vilgrain V, Schmutz G, Oyen R, et al. Characterization of focal liver lesions with SonoVue-enhanced sonography: International multicenter-study in comparison to CT and MRI. World $J$ Gastroenterol 2009; 15 (30): 3748-56.

25. D'Onofrio M, Crosara S, De Robertis R, Canestrini S, Mucelli RP. Contrast-Enhanced Ultrasound of Focal Liver Lesions. AJR Am J Roentgenol 2015; 205 (1), 56-66.

26. Zarzour JG, Porter KK, Tchelepi H, Robbin ML. Contrast-enhanced ultrasound of benign liver lesions. Abdominal Radiology 2018; 43, 848-60. 